\title{
Modelagem de uma Ontologia de Domínio com Foco em Competências para Sistemas de Recomendação na Educação
}

\author{
Title: Modeling a Domain Ontology focused in Competencies for Recommendation Systems in \\ Education
}

\author{
Augusto Simon \\ Universidade Federal do Rio Grande \\ do Sul \\ uclguto@gmail.com \\ Bruna Kin Slodkowski \\ Universidade Federal do Rio Grande \\ do Sul \\ brunakinnuted@gmail.com
}

\author{
Patricia Alejandra Behar \\ Universidade Federal do Rio Grande \\ do Sul \\ pbehar@terra.com.br \\ Sílvio César Cazella \\ Universidade Federal do Rio Grande \\ do Sul \\ silvio.cazella@gmail.com
}

\author{
Cristina Alba Wildt Torrezzan \\ Universidade Federal do Rio \\ Grande do Sul \\ crisawt.ufrgs@gmail.com \\ Daisy Schneider \\ Universidade Federal do Rio \\ Grande do Sul \\ daisy.schneider@gmail.com
}

\begin{abstract}
Resumo
Este artigo relata o resultado de um estudo que integra os Sistemas de Recomendação (SRs) - os quais têm tido seu uso ampliado diante da quantidade de conteúdos disponibilizados na web; as ontologias - visto sua contribuição no apoio a aprendizagem de conceitos de um domínio; e as competências no campo da Educação - as quais também assumem importância como perspectiva formativa. A motivação deste trabalho justifica-se nos embaraços normalmente encontrados, por professores e alunos, durante a utilização de Sistemas de Recomendação educacional baseados em competências. Esses usuários, por vezes, possuem dificuldades em entender o conceito de competências e a sua conexão com atividades de ensino e recursos educacionais do Sistema de Recomendação. $O$ objetivo, portanto, é apresentar a modelagem, implementação e verificação de uma ontologia de domínio, com foco em competências, voltada a Sistemas de Recomendação Educacional (SREs). Como método, são descritas as etapas de modelagem, a implementação com o software Protégé e a linguagem owl e o seu processo de verificação. O software permitiu a sua avaliação quanto a definição adequada dos axiomas da ontologia e a utilização de requisições em seu sistema de inferência. A metodologia adotada e modificada, a 101, e a estrutura da ontologia modelada foram discutidas com alunos de uma disciplina de pós-graduação em informática na educação. Como resultado, verificouse a pertinência da utilização da ontologia proposta em Sistemas de Recomendação educacional. Desse modo, pretende-se disponibilizá-la à comunidade acadêmica e apoiar professores e alunos no uso de SRE baseados em competências.
\end{abstract}

Palavras-chave: Ontologias, Competências, Sistemas de Recomendação Educacional.

\begin{abstract}
This article reports the result of a study that integrates Recommendation Systems (RSs) - which have had their use expanded due to the amount of content available on the web; ontologies - given their contribution in supporting the learning of concepts of a domain; and competences in education field - which also assume importance as a formative perspective. The motivation of this work is justified by the embarrassments normally faced by teachers and students when using Educational Recommender Systems (ERSs) based in competencies. These users sometimes have difficulty in understanding the concept of competencies and its connection with teaching activities and educational resources of the recommendation system. The objective, therefore, is to present the modeling, implementation and verification of a domain ontology, focused on competencies, for use in Educational Recommender Systems. As a method, the modeling steps are described as well as Protégé software and owl language implementation and evaluation process.
\end{abstract}

Cite as: Simon, A.; Behar, P. A.; Torrezzan, C. A. W.; Slodkowski, B. K.; Cazella, S. C. \& Schneider, D. (2020). Modeling a Domain Ontology focused in Competencies for Recommendation Systems in Education (Modelagem de uma Ontologia de Domínio com Foco em Competências para Sistemas de Recomendação na Educação). Brazilian Journal of Computers in Education (Revista Brasileira de Informática na Educação - RBIE), 28, 644-663. DOI: 10.5753/RBIE.2020.28.0.644 
The software allowed its evaluation concerning suitable axioms definition and required use in its inference system. The adopted and modified 101 methodology and the modeled ontology structure were discussed with students of a postgraduate course in computer science in education. As a result, the relevance of using the proposed ontology in educational recommendation systems was verified. Thus, it is intended to make it available to the academic community and to support teachers and students in the use of ERS based in competencies.

Keywords: Ontologies, Competencies, Educational Recommender Systems. 


\section{Introdução}

Este artigo tem como objetivo apresentar a modelagem, implementação e verificação de uma ontologia de domínio, voltada a Sistemas de Recomendação baseados em competências. Como método, descreve-se as etapas de modelagem, a implementação com o software Protégé ${ }^{1}$ e a linguagem $\mathrm{OWL}^{2}$, além do seu processo de verificação. Almeja-se, assim, apoiar alunos e professores em ações que envolvam o cadastramento, avaliação ou associação de competências a Objetos de Aprendizagem (OAs) e atividades de ensino, para aperfeiçoamento do processo de recomendação. Para tanto, adota-se a concepção de competências elaborada por Behar et al. (2013).

A utilização de SREs surge da necessidade de filtragem da grande diversidade de recursos digitais encontrados na web, relatada em Behar et al. (2015), entre eles os Objetos de Aprendizagem (OAs). Normalmente, o sujeito necessita despender tempo e dedicação no processo de seleção, visualização e avaliação dos materiais disponibilizados, mesmo utilizando repositórios $^{3}$. Através dos sistemas de recomendação, tem-se a possibilidade de disponibilizar recursos educacionais ao usuário de acordo com as suas demandas, inferidas a partir dos feedbacks fornecidos ao sistema.

Um dos desafios a ser enfrentado para que a utilização de SRs possa de fato contribuir na educação é a definição adequada da relação de interesses entre as expectativas dos seus usuários e as recomendações recebidas (CAZELLA et al., 2014). Uma solução apresentada por Behar et al. (2015) para esse problema se encontra na associação do conceito de competências aos interesses de estudo dos alunos e aos itens didáticos a serem recomendados. Assim, o sistema poderá indicar recursos educacionais de acordo com as competências que os usuários necessitarem aprimorar ou construir.

No entanto, o termo competências consiste em um conceito complexo, podendo apresentar várias perspectivas ou entendimentos a seu respeito. O presente estudo adota o conceito de Behar et al. (2009) e Zabala e Arnau (2014), considerando competências como o conjunto de conhecimentos, habilidades e atitudes (CHA) necessários para a realização de uma determinada tarefa de forma eficiente e eficaz. Assim, a descrição e/ou associação de competências a disciplinas e recursos didáticos, em SREs, por vezes, pode configurar uma tarefa árdua, pois tornase necessário a identificação e definição de todas as competências envolvidas, assim como do CHA de cada uma delas. Dessa forma, essa ação, além de minuciosa, aprofundada e extensa, requer a aplicação de um conhecimento especializado (BEHAR et al., 2013).

Uma alternativa para resolver essa questão pode ser a utilização de ontologias que atuem como um modelo de organização e compartilhamento de informações. Tal proposta é explorada em trabalhos como os de Bremgartner, Netto e Menezes (2015) ou Paquette (2015). Dessa forma, é possível disponibilizar ao usuário desse tipo de SRE, as informações especializadas sobre cada competência, bem como de sua relação entre elas e com as disciplinas e recursos didáticos cadastrados no recomendador. Um sistema apoiado por ontologias poderia ser aplicado para sugerir as competências mais indicadas para serem associadas aos recursos educacionais e disciplinas no momento de seu cadastro (e já com todos os conhecimentos, habilidades e atitudes

\footnotetext{
${ }^{1}$ Disponível em: http://protege.stanford.edu/.

2 A OWL (do inglês Web Ontology Language) consiste em uma linguagem utilizada para descrever ontologias na web, utilizada no software Protégé (W3C Semantic Web, 2012)

${ }^{3}$ Repositórios são bases de dados online que disponibilizam a produção científica de uma área temática ou instituição, organizada por metadados (assunto e/ou palavras-chave) (IBICT - Instituto Brasileiro de Informação em Ciência e Tecnologia, 2018).
} 
identificados), reduzindo a complexidade e o tempo normalmente envolvidos nessas ações.

Neste contexto, a ontologia pode ser entendida como um esquema que envolve diferentes conceitos, relacionando-os entre si e delineando a sua interpretação. Mostra-se eficaz, portanto, não apenas em sistemas computacionais, mas também no atendimento das necessidades de especialistas para compartilhar informações e a novos usuários no aprendizado sobre o significado dos termos do domínio (NOY e MCGUINNESS, 2001). Diante disso, pode auxiliar no planejamento e nas práticas educacionais, especialmente quando relacionada a recursos digitais. Seguindo essa perspectiva, realizou-se a modelagem de uma ontologia, no domínio das competências, como forma de auxiliar a ação de alunos e professores durante a utilização de um Sistema de Recomendação Educacional.

A partir desse cenário, são comentados a seguir, ao longo de seis seções, os principais conceitos e procedimentos envolvidos no processo de modelagem e validação da ontologia proposta. Inicia-se com a apresentação dos aspectos conceituais relacionados à utilização de Sistemas de Recomendação baseados em competências e a modelagem de ontologias na educação. Em seguida, já na quarta seção, aborda-se a metodologia seguida para a modelagem da ontologia proposta, com descrição do processo realizado, a verificação com o software e as atividades realizadas com alunos de pós-graduação. Na penúltima seção são discutidos os resultados obtidos. A sexta seção traz as considerações finais.

\section{Sistemas de Recomendação, Objetos de Aprendizagem e Competências: Aspectos Conceituais}

Os Sistemas de Recomendação são compostos por ferramentas e técnicas de software focadas em recomendar itens com alta probabilidade de interesse a um determinado usuário (RICCI et al, 2015). Originaram-se com as primeiras redes de comunicação por computador, atuando em situações marcadas pelo excesso de informação (RESNICK et al., 1997). Inicialmente, tais sistemas foram aplicados no controle de listas de e-mails e na recomendação de notícias. Em seguida, houve uma popularização dessa ferramenta no comércio eletrônico. Então, passam a ser utilizados em áreas que envolvem entretenimento e conteúdo, tais como as aplicações educacionais, os serviços e as mídias sociais (RICCI et al., 2015).

O desafio enfrentado pelos desenvolvedores de SRs é estabelecer uma adequada relação entre as necessidades dos seus usuários e os recursos a eles recomendados (CAZELLA et al., 2014). Uma das estratégias utilizadas para resolver esse ponto em SRs voltados à educação consiste em acrescentar o conceito de competências a tal associação, como é o caso do sistema utilizado nesta pesquisa (BEHAR et al. 2015).

Segundo Behar et al. (2013), as competências são compostas por três elementos: Conhecimentos (C) - saber conhecer, Habilidades (H) - saber fazer, e Atitudes (A) - saber ser/conviver, os quais são resumidos na sigla CHA. Diante de um problema ou novidade, o sujeito mobiliza esses elementos para resolver ou superar as questões envolvidas na situação. Os autores defendem a aplicação das competências no contexto educacional pela perspectiva baseada na Epistemologia Genética de Jean Piaget, o que traz um componente de aprendizagem e a construção constante das competências.

Entre os SRs utilizados na área educacional, destaca-se a recomendação de Objetos de Aprendizagem, tipo predominante na literatura acadêmica (IBRAHIM et al., 2019). Para Wiley (2011), OAs consistem em recursos digitais que podem ser reutilizados para mediar a aprendizagem. A revisão da literatura realizada por Drachsler et al. (2015) também enfatiza a recomendação de OAs na educação. 
Seguindo essa perspectiva, os Sistemas de Recomendação de Objetos de Aprendizagem por competências denotam uma possível forma de unir OAs a competências, sob um viés educacional. $\mathrm{O}$ intuito é indicar recursos educacionais aos usuários a partir das competências que necessitam aprimorar ou construir. No entanto, torna-se necessário que professores e alunos, ao utilizarem o sistema, preencham formulários envolvendo descrições e avaliações segundo competências, procedimento que, por vezes, fornece complexidade à utilização dos recomendadores. Esse fato pode ser observado, por exemplo, nos sistemas baseados em competências discutidos em Behar et al. (2015) e Cazella et al. (2014), Cazella, Reategui e Behar (2010). Eles dependem da associação manual de competências a perfis de OAs, atividades de ensino e auto-avaliação de estudantes. Porém, esse processo requer algum conhecimento sobre o assunto para evitar a vinculação de competências a OAs e atividades de ensino que não possuam relações com as mesmas (BEHAR et al., 2013). Mesmo entre os profissionais da educação, que compreendem o conceito de competências, costuma haver divergências no que diz respeito à sua definição em função da complexidade do termo (BEHAR et al., 2013).

Verifica-se, desse modo, a necessidade de auxiliar os usuários de SRs baseados em competências na correta vinculação dos seus conceitos em cada aplicação. Uma possibilidade de auxílio, conforme apresentada em trabalhos como o de Bremgartner, Netto e Menezes (2015) ou Paquette (2015), consiste na utilização de ontologias de domínio para a representação de modelos de competências.

Dessa forma, as correlações entre competências, objetos de aprendizagem e disciplinas poderiam ser realizadas automaticamente pelo sistema, sem depender da ação direta do professor. Neste sentido, a seguir são analisadas algumas pesquisas que apresentam ontologias para o domínio de competências aplicadas a Sistemas de Recomendação na educação.

\section{Ontologias: Aplicações Voltadas à Educação}

A Ontologia, tradicionalmente, consiste em uma disciplina especial da filosofia e esta expressão foi utilizada pela primeira vez em 1606, no livro Ogdoasscholastica, de Jacob Lorhard, como sinônimo de metafísica (ØHRSTRØM, ANDERSEN e SCHÄRFE, 2005). O termo sofreu um processo de ressignificação, inicialmente por pesquisadores da área da inteligência artificial, na Ciência da Computação Simon (2020). Após, em 1980, foi introduzido nessa área através da discussão sobre as informações que deveriam estar incluídas no entendimento comum a respeito do mundo (GRUBER, 2009).

Thomas R. Gruber, em 1993, define a ontologia como uma especificação explícita de uma conceitualização, enunciado que se torna bastante popular e debatido. Nesse sentido, pode ser considerada como um modelo cujos conceitos devem representar certa realidade (NOY e MCGUINNESS, 2001). Nesse contexto, a ontologia passou a ser utilizada como um modelo para a organização e o compartilhamento de conhecimento entre diferentes entidades, seres humanos ou sistemas computacionais (SIMON, 2020).

As contribuições de ontologias à pesquisa e em áreas diversas pelo seu potencial para o compartilhamento e apresentação de informações são sintetizadas e categorizadas por Gavrilova e Leshcheva (2015), como pode ser observado na Figura 1. As autoras estruturam a sua utilização partindo dos seguintes aspectos:

- Propósito e domínio: ligados ao emprego da ontologia e à sua área de aplicação;

- Relacionamento: associação entre os conceitos representados;

- Metodologia: refere-se ao seu processo de modelagem;

- Formalização: trata da apresentação das informações contidas no modelo; 
- Proprietário ou mantenedor: indica os responsáveis pela sua gestão e manutenção.

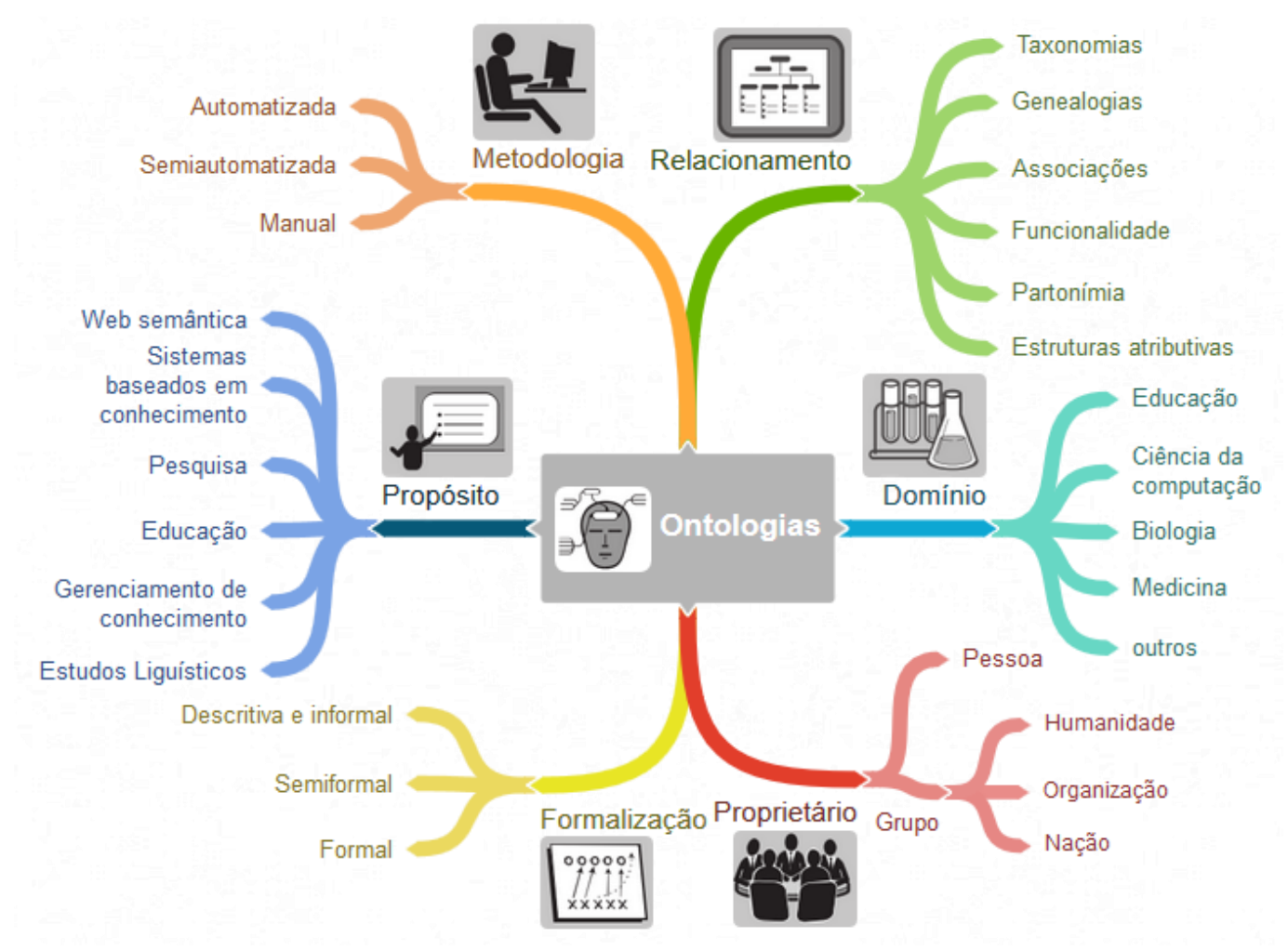

Figura 1: Contribuições das ontologias à pesquisa. Adaptado de Gavrilova e Leshcheva (2015), elaborado por Simon (2020).

A utilização de ontologias na educação tem se mostrado promissora no apoio a projetos tanto na modalidade presencial quanto a distância. A revisão da literatura realizada por Yahya, George e Alfaries (2015) classifica tarefas desempenhadas pelas ontologias na educação a distância. As relacionadas à personalização do processo de aprendizagem são as mais presentes nos artigos avaliados, seguidas da busca e recuperação de recursos educacionais; modelamento de perfil de alunos; descrição do domínio de aprendizado; e demais tarefas menos frequentes.

O trabalho de revisão da literatura de Tarus, Niu e Mustafa (2017), atesta a larga utilização de ontologias em SRs na educação e conclui que esses modelos podem contribuir com a melhoria da acurácia das recomendações, além de atenuar dificuldades enfrentadas de forma geral nesses sistemas. O papel das ontologias ainda é abordado por Mendes Neto e Sales (2015) como forma de enriquecimento semântico em SRs, associando conceitos e comentários a palavras-chave ou metadados utilizados no sistema. Outra contribuição importante é apresentada por Gomez, Huete e Hernandez (2016), visto que elaboraram um sistema sensível ao contexto, apoiando a aprendizagem ativa dos alunos. Essa questão é especialmente importante quando relacionada às competências, uma vez que é um aspecto essencial no seu conceito e para a perspectiva formativa delas. Em sua arquitetura, o sistema inclui capacidade de raciocínio de modo que a ontologia baseada em contexto seja capaz de fornecer recursos eficientes para o processo de aprendizagem de cada usuário.

Ibrahim et al. (2019), por sua vez, desenvolveram um sistema de filtragem híbrida, chamado de recomendação de curso personalizada baseada em ontologias, sendo outro fator importante que se relaciona com o estudo em questão. Na seção a seguir aborda-se especificamente a modelagem e aplicação de ontologias de domínio com foco em competências como estratégia de auxílio para as recomendações em SRs baseados em competências. 


\subsection{Ontologias de Domínio e Competências: Trabalhos Relacionados}

Neste estudo buscou-se conhecer projetos que abordassem o uso de ontologias na área educacional. Quatro trabalhos de destacam ao propor ontologias para a representação de competências a serem utilizadas em SRs na educação.

As especificações de ontologias para modelos de usuários voltadas a sistemas adaptativos são apresentadas por Dolog e Nejdl (2007), com o intuito de permitir a recomendação de recursos em ambientes educacionais. Competência, para os autores, consiste apenas em uma propriedade da classe "performance" que liga a informação de desempenho de um usuário a um determinado conceito.

No caso do trabalho de Rezende et al. (2015), descreve-se a ontologia denominada "Personna" voltada para a modelagem do perfil e do contexto do aluno em um ambiente de educação a distância com recomendação de OAs. Cada competência nessa ontologia é definida através de uma frase.

A estrutura intitulada como "Ampara" é apresentada por Bremgartner, Netto e Menezes (2015). Trata-se de uma estratégia que permite a adaptação de recursos para estudantes em AVAs e o seu acompanhamento ao longo da atividade de ensino. Cada competência na ontologia descrita é expressa por um conjunto de habilidades.

Por fim, destaca-se o trabalho de Paquette (2015) pela proximidade com a proposta desta pesquisa, utilizando ontologias para a representação de competências. O autor apresenta um método comparativo de competências para agentes assistivos na personalização do ensino e para SRs. O seu modelo define o conceito de competências através de três elementos: aptidões, níveis de performance e conhecimentos.

Apenas o trabalho de Paquette (2015), entre os avaliados, se aproxima da proposta de modelagem deste estudo, visto que adota um conceito de competências com um grau mais elevado de complexidade e profundidade. Os dois trabalhos diferem-se, entretanto, no entendimento do conceito. Esta pesquisa adota o modelo de competências defendido por Behar et al. (2013), o considerando mais adequado ser o único estudado que considera os conhecimentos, o "saber", as habilidades, o "saber fazer" e as atitudes, o "saber ser", como bases necessárias às competências do sujeito. Além disso, Paquette (2015) não disponibiliza a sua ontologia, de forma que possa ser reutilizada e adaptada.

Sendo assim, os quatro trabalhos referenciados nesta seção consistem nos mais próximos ao objetivo deste estudo: a modelagem de uma ontologia de domínio, com foco em competências, voltada a Sistemas de Recomendação Educacional (SREs). As informações sobre o domínio de competências presentes nas ontologias descritas por seus autores podem ser visualizadas na Tabela 1.

Tabela 1. Comparação entre os domínios de diferentes ontologias utilizadas em Sistemas de Recomendação na educação.

\begin{tabular}{|l|l|}
\hline \multicolumn{1}{|c|}{ Autores } & \multicolumn{1}{c|}{ Domínio da Ontologia } \\
\hline Dolog e Nejdl (2007) & Modelo de aluno, com competência como característica de uma dimensão. \\
\hline Rezende et al.(2015) & Modelo de aluno e do seu contexto, com competência como característica de uma dimensão. \\
\hline $\begin{array}{l}\text { Bremgartner, Netto e } \\
\text { Menezes (2015) }\end{array}$ & Modelo de aluno, com competência como conjunto de habilidades. \\
\hline Paquette (2015) & $\begin{array}{l}\text { Modelo de competências, compostas por três elementos: aptidões, níveis de performance } \\
\text { e conhecimentos }\end{array}$ \\
\hline
\end{tabular}

A seção a seguir trata de metodologias para a modelagem de ontologias e qual estratégia foi seguida para a modelagem descrita neste trabalho. 


\subsection{Metodologias para a Modelagem da Ontologia de Domínio na Educação}

A modelagem de uma ontologia consiste em um processo complexo e multidisciplinar que envolve especialistas em ontologias e no domínio da realidade em questão, o que tem gerado o desenvolvimento e proposição de diversas metodologias (IQBAL et al., 2013). Torna-se importante destacar que, segundo a concepção teórica adotada por esta pesquisa, no âmbito do presente estudo reporta-se o termo modelagem à construção de ontologia.

A análise realizada por Iqbal et al. (2013) compara quinze metodologias populares utilizadas em modelagens na literatura acadêmica. Os autores destacam três métodos: METHONTOLOGY, 101 e UPON. Todas seguem um modelo de prototipação evolutivo, que prevê o refinamento da ontologia ao longo da sua modelagem. Além disso, podem ser aplicadas com independência de domínio, fornecendo detalhes suficientes para a execução das técnicas e atividades previstas em seus processos.

A Methontology (JONES et al., 1998) é voltada à construção de ontologia desde seu ponto zero (FERNÁNDEZ-LÓPEZ et al., 1997). Abrange as atividades e técnicas empregadas em detalhes. Aborda o nível do conhecimento, baseado na progressão de protótipos. Em suas etapas, envolve atividades orientadas ao desenvolvimento, especificação, conceituação, formalização, integração e implementação. Aborda principalmente a especificação de requisitos, conceitualização do domínio do conhecimento, implementação de um modelo formal, formalização do modelo conceitual em uma linguagem formal e manutenção de ontologias implementadas (MORAES e AMBRÓSIO, 2007).

Por sua vez, a UPON (NICOLA et al., 2005) envolve ciclos, iterações e fluxos de trabalho. Seu diferencial está no uso orientado, iterativo e em sua natureza incremental. Sendo assim, é normalmente indicada para o processo de engenharia de ontologias. Por outro lado, não aborda profundamente aspectos colaborativos de construção.

Já a Metodologia 101 (NOY e MCGUINNESS, 2001) possui uma natureza iterativa, baseada em regras fundamentais que apoiam a tomada de decisões de projeto durante a construção de ontologia. Suas etapas envolvem todo o processo de desenvolvimento, inclusive contemplando a definição de hierarquias de classe e propriedades de classes e instâncias.

Essas três metodologias constituem padrões conhecidos e normalmente utilizados nas áreas de engenharia de software e representação do conhecimento (IQBAL et al., 2013). Seguem um modelo de evolução de protótipos e suas naturezas comportam-se de forma independente em relação à aplicação, além de fornecerem um certo nível de detalhamento a respeito das técnicas e atividades empregadas (IQBAL et al., 2013). A Methontology, por detalhar seus procedimentos, acaba envolvendo um número significativo de atividades. A UPON salienta-se pela abordagem de ciclos e alguns procedimentos de uso orientado, interativos e de natureza incremental. No entanto, já não contempla, de forma tão intensa, o aspecto colaborativo da construção. Nesse sentido, nesta pesquisa, optou-se pela adoção da metodologia de Noy e Mcguinness (2001) intitulada "101", devido a abordar todas as etapas do processo de modelagem e se adequar melhor a equipes multidisciplinares compostas por profissionais de áreas tecnológicas e da educação, se apresentando mais compreensível e acessível.

A descrição, a utilização da metodologia 101 e as adaptações realizadas em seus passos são descritas na seção seguinte. É apresentada assim a modelagem da ontologia de domínio, com foco em competências, voltada a Sistemas de Recomendação Educacional (SREs), bem como a sua implementação e testagem através do software Protégé e a linguagem OWL. São descritas também atividades realizadas com alunos de uma disciplina de pós-graduação em informática na educação, que consistiram na utilização da metodologia 101 adaptada e em discussões sobre os elementos básicos sobre competências que devem estar presentes em uma ontologia de domínio. 


\section{Processo de Construção de uma Ontologia de Domínio de Competências}

A modelagem da ontologia de domínio de competências foi efetuada com base nas atividades descritas a metodologia 101 (NOY e MCGUINNESS, 2001). A seção a seguir apresenta os seus passos originais e quais modificações foram realizadas.

\subsection{A Metodologia 101 e as Adaptações Realizadas}

Originalmente, a metodologia 101 preconiza sete passos, a saber:

- primeiro passo - determinação do domínio e do escopo da ontologia, realizada através da resposta a questões pré-definidas;

- $\quad$ segundo passo - análise para reutilização de ontologias, quando são avaliadas as ontologias existentes e a possibilidade da reutilização das mesmas na modelagem da nova ontologia;

- terceiro passo - enumeração dos termos importantes da ontologia, que auxiliarão na definição das classes e dos slots;

- quarto passo - definição das classes e a sua hierarquia, realizada através das respostas obtidas nos passos anteriores e seguindo-se uma das três abordagens propostas a seguir;

- quinto passo - definição das características das classes - os slots, considerando-se as respostas, principalmente, do terceiro passo;

- $\quad$ sexto passo - definição das facetas dos slots, descrevendo os seus tipos de valores, a quantidade de valores, e outras regras relativas a elas;

- $\quad$ sétimo passo - criação das instâncias, considerando-se as instâncias individuais de cada classe na hierarquia.

Tais passos da metodologia 101 foram seguidos pelos autores deste artigo e por 36 alunos dos programas de Pós-Graduação em Educação e em Informática na Educação da Universidade Federal do Rio Grande do Sul que estiveram matriculados em duas edições de disciplina de pósgraduação. Esses alunos realizaram atividades referentes a modelagem de ontologias de domínio para aplicações na área da educação e preencheram questionários abordando essas atividades.

Os resultados obtidos com esses sujeitos não fazem parte do foco deste estudo. Entretanto, as suas experiências e respostas em relação ao uso da metodologia permitiram a identificação de possíveis adaptações, tendo-se em vista equipes multidisciplinares com integrantes sem experiência prévia nas áreas tecnológicas. Dessa forma, a sua nomenclatura foi traduzida para o português e simplificada, bem como foram combinados os passos 5 e 6 .

Em relação à nomenclatura utilizada inicialmente, dois termos se destacaram negativamente em relação ao entendimento dos alunos: slot e faceta. Slots podem ser entendidos por Noy e Mcguinnes (2001) como as propriedades das classes e as facetas dizem respeito às informações que descrevem essas propriedades. Assim, o termo slot foi substituído pelo seu sinônimo propriedade. Já faceta foi substituído pelo correspondente descrição. Esses termos estão em acordo também com a versão do Protégé utilizada durante as aulas, a 5.2.

Quanto a unificação dos passos 5 e 6, essa decisão foi tomada por se tratarem dos que foram considerados pelos alunos como os mais complexos e repetitivos e são os que fazem uso dos termos alterados. Assim, o quinto passo, "definir as características das classes - os slots", e o sexto "descrever as facetas dos slots", tornaram-se um novo quinto passo: "definir as propriedades das classes". Esse passo modificado considera que a apresentação das propriedades pode ser realizada em conjunto com a descrição dos seus elementos.

A seção a seguir descreve a utilização da metodologia adaptada abordando-se cada um dos 
seis passos na modelagem da ontologia de domínio de competências.

\subsection{Modelagem da Ontologia a partir da Metodologia Adaptada}

Os seis passos apresentados nesta seção consistem em uma adaptação da Metodologia 101, descrita por Noy e Mcguinness (2001). Ao longo da sua apresentação, a modelagem da ontologia de domínio de competências, objetivo deste estudo, é explicitada. Após, são realizadas as verificações pertinentes através do software Protégé.

Primeiro passo: devem ser respondidas quatro questões iniciais: o domínio que a ontologia irá cobrir; a função que essa irá desempenhar; que tipo de perguntas a ontologia deve responder; e quem vai usá-la e mantê-la.

Sobre o domínio a ser coberto, a modelagem da ontologia descrita no presente estudo utiliza como base o modelo de competências apresentado Behar et al. (2013). As instâncias, ou indivíduos, inicialmente adicionados à ontologia baseiam-se no mapeamento de competências digitais desenvolvido por Silva e Behar (2016), a título de exemplo. Tais competências são compostas por conhecimentos, habilidades e atitudes (CHA) e podem ser mobilizadas nas situações que exigem dos sujeitos a utilização de recursos digitais e ferramentas tecnológicas dentro de um contexto (SILVA e BEHAR, 2016).

As funções a serem desempenhadas consistem no apoio a professores e alunos usuários de SREs baseados em competências através de duas contribuições. A primeira diz respeito a apresentação visual dos conceitos relacionados às competências e os seus CHAs, armazenados na ontologia. A segunda, visa apoiar os usuários no processo de associação do conceito aos recursos educacionais a partir da recomendação de competências específicas a serem vinculadas a atividades de ensino ou Objetos de Aprendizagem.

A apresentação visual dos conceitos relacionados às competências pode ser exemplificada através da Figura 2, tratando do conceito de competências de uma forma geral, e da Figura 3, que exibe uma competência específica genérica.

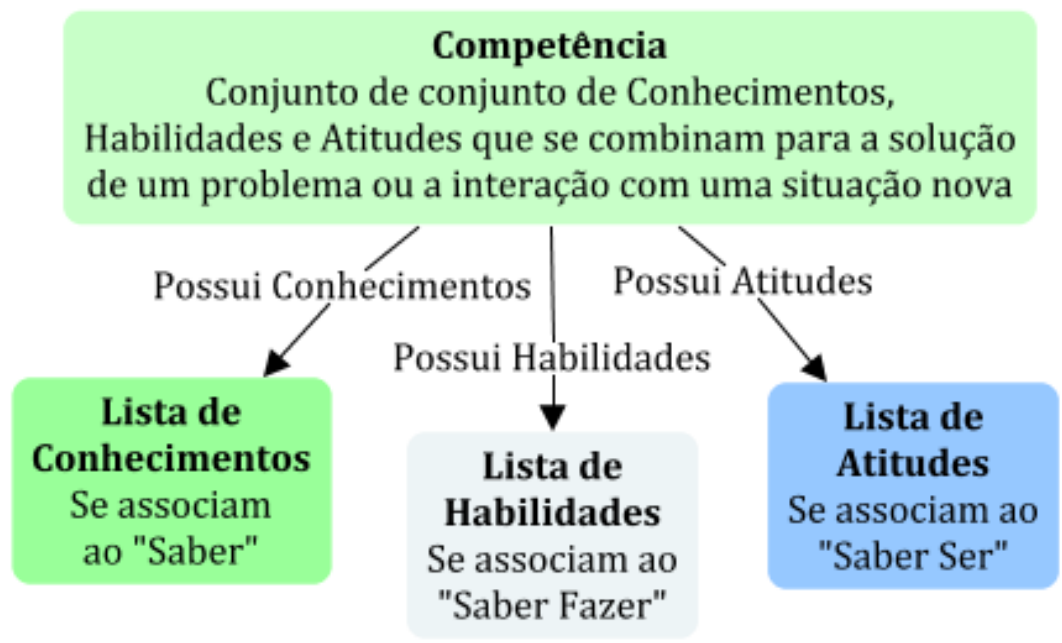

Figura 2: Conceitos relacionados às competências em geral. Simon (2020). 


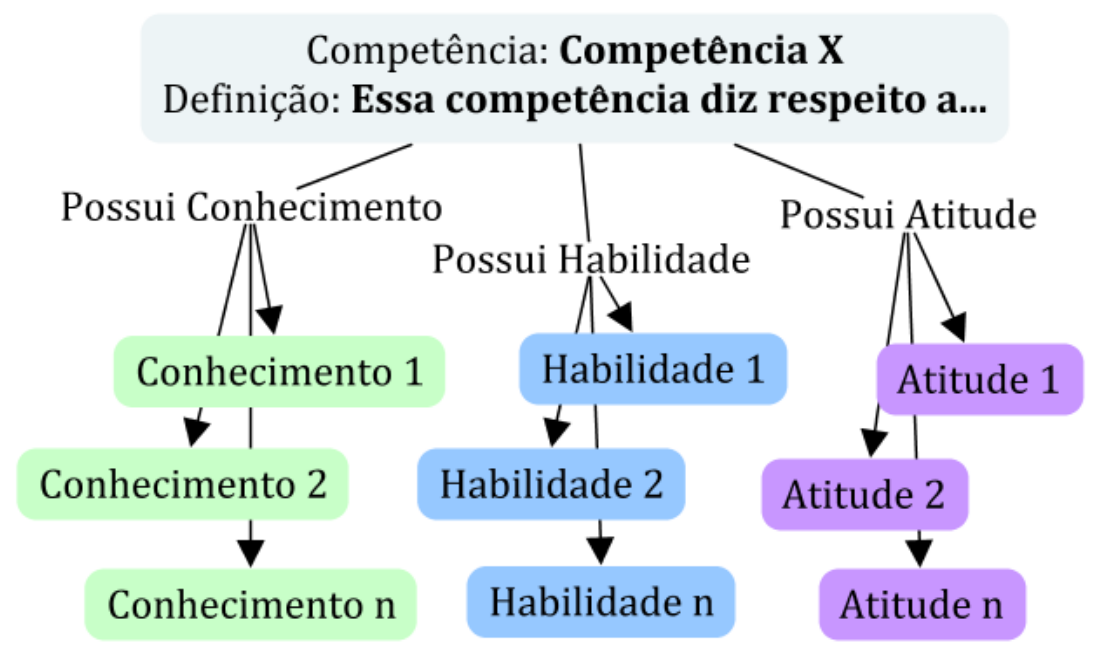

Figura 3: Conceitos relacionados a uma dada competência. Simon (2020).

A recomendação de competências específicas a serem vinculadas a atividades de ensino ou Objetos de Aprendizagem se dá através da inclusão de palavras-chave na ontologia referentes aos elementos que compõem as competências e aos metadados que descrevem os OAs ou as atividades de ensino. A comparação desses termos para a realização da recomendação é ilustrada na Figura 4.

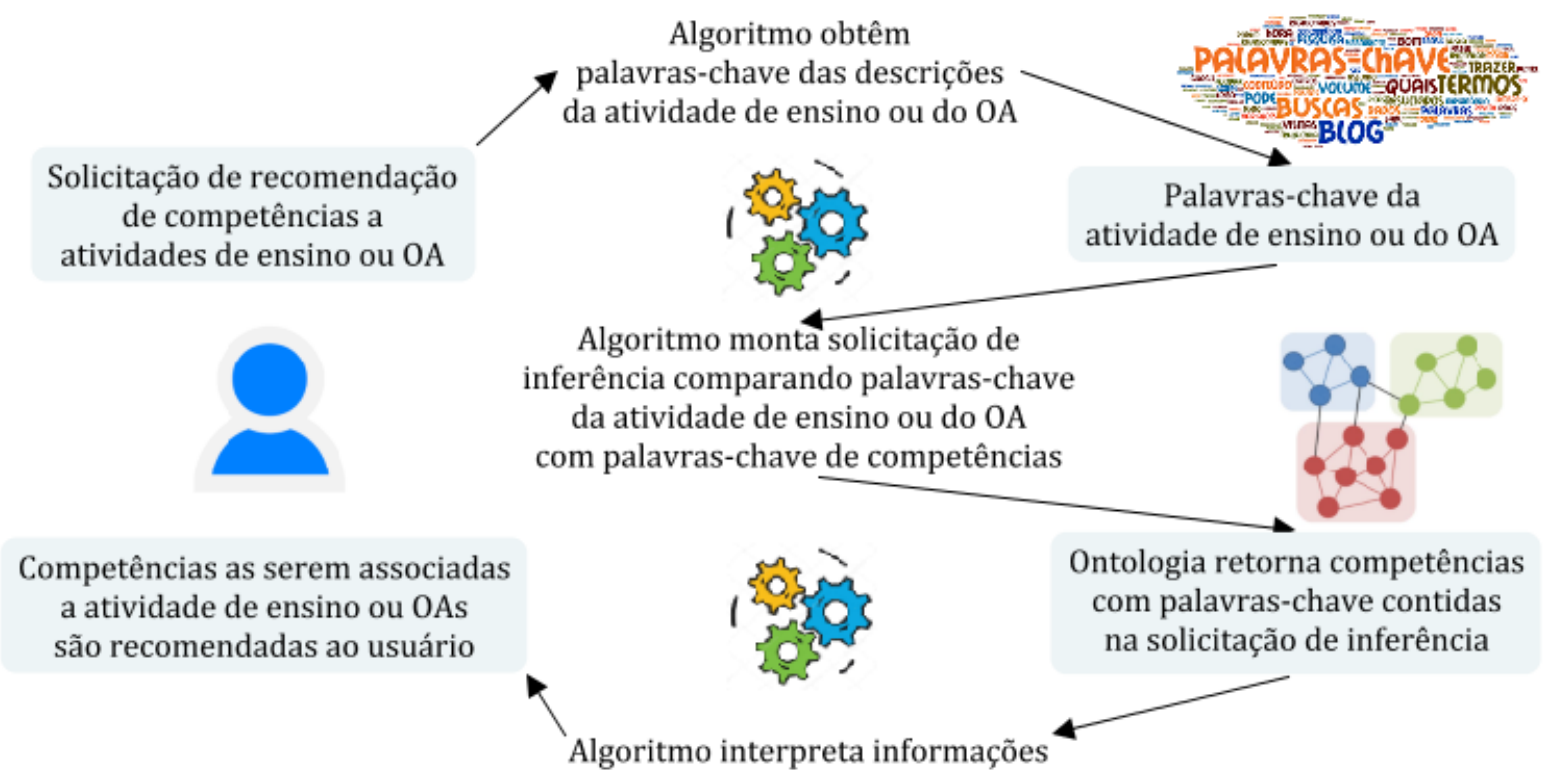

Figura 4: Recomendação de competências. Simon (2020).

As perguntas que a ontologia deve responder são três:

- quais competências específicas que se relacionam a certos elementos fornecidos?

- quais elementos estão presentes em uma dada competência?

- quais competências específicas possuem uma ou mais palavras-chave requisitadas?

Uma forma de implementação da terceira pergunta é apresentada na Figura 4. A implementação das perguntas 1 e 2 são ilustradas pela Figura 5. 


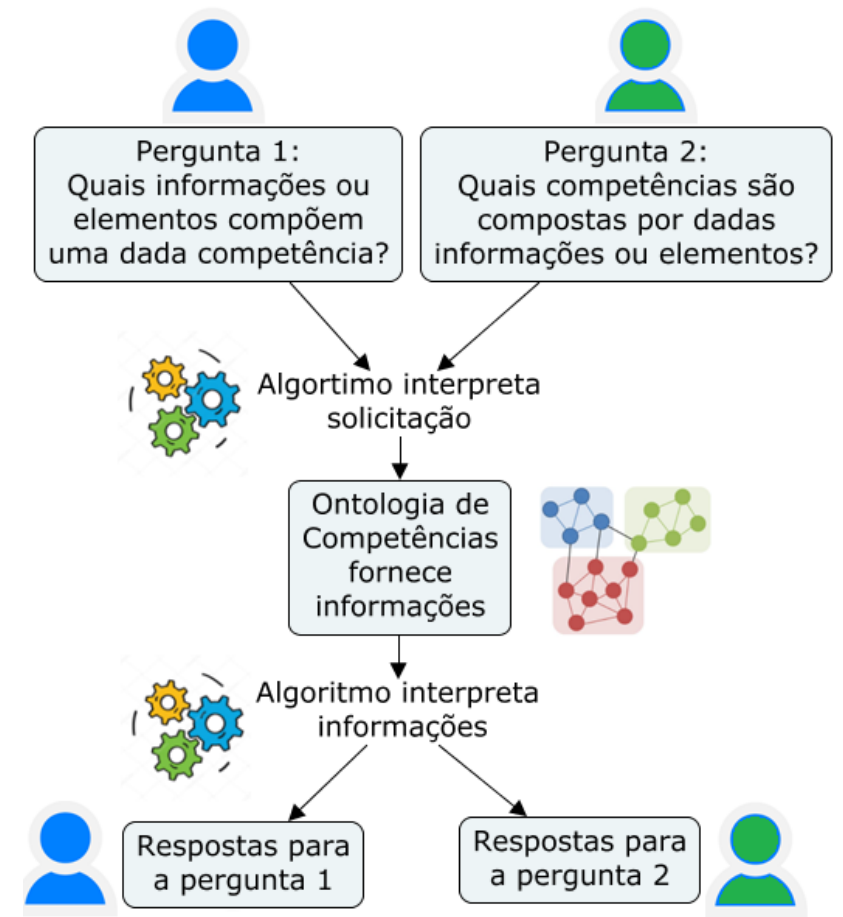

Figura 5: Utilização da ontologia pelos algoritmos de um dado sistema. Simon (2020).

Os usuários e mantenedores da ontologia serão, inicialmente, os pesquisadores associados à pesquisa descrita neste estudo. Como ela será disponibilizada publicamente, outras pessoas e grupos de pesquisa poderão vir a utilizá-la em seus projetos, ampliando-a ou adaptando-a a sua reutilização.

Segundo passo: considerar a reutilização de ontologias. Não foram identificadas na literatura acadêmica ontologias de domínio modeladas com base no conceito de competências conforme adotado neste projeto ou que pudessem de fato serem reutilizadas. A seção 3.1 discute essas diferenças e impossibilidades.

Terceiro passo: enumerar termos importantes da ontologia. Os termos que dizem respeito apenas a uma ou outra competência específica não farão parte da estrutura desta ontologia, podendo estarem presentes como instâncias das classes definidas nos passos seguintes. Os termos adotados são: domínio, competência geral, competência específica, conhecimento, habilidade, atitude, nome, definição e palavra-chave.

Quarto passo: definir as classes e a sua hierarquia. Foram determinados os conceitos mais gerais do domínio e a sua especialização por meio da criação de subclasses. Seguindo a ordem hierárquica, têm-se as classes: Domínio, Competência Geral, Competência Específica e as três classes irmãs (siblings) Conhecimento, Habilidade e Atitude. A hierarquia taxonômica de classes, construída através do software Protégé, e apresentada na Figura 6.

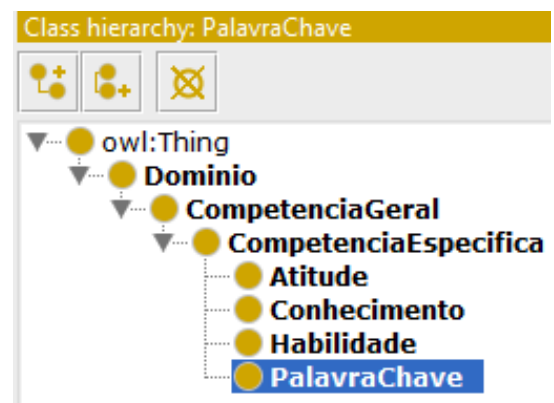

Figura 6: Hierarquia taxonômica de classes, construída através do Protégé. Simon (2020). 
Quinto passo: estabelecer as propriedades das classes.

Neste passo foram definidos os atributos e relacionamentos das classes que descrevem os conceitos relacionados às competências. Além dos atributos, associados aos valores que cada classe pode possuir, foram especificados os relacionamentos que ligam uma classe às suas classes de nível superior, inferior e mesmo nível, quando existirem. Os atributos definidos são dois: nome e definição. Já os relacionamentos são 12: "temCompetenciaGeral", "temCompetenciaEspecifica", "temConhecimento","temHabilidade", "temAtitude", "ehCompetenciaEspecificaDe", "ehCompetenciaGeralDe", "ehConhecimentoDe", "ehHabilidadeDe", "ehAtitudeDe", "ehPalavraChaveDe" e "temPalavraChave".

A Figura 7 apresenta em detalhes os resultados obtidos com o quinto passo. Os atributos são representados pelas caixas amarelas e os relacionamentos pelas caixas azuis, enquanto que as classes são indicadas pelas caixas verdes. O tipo de valor que cada propriedade receberá é indicado pelas caixas roxas. Já as cinzas determinam a variedade de informações que podem ser associadas a elas. Cada classe possui um atributo nome, que indicará o nome de cada instância a ser adicionada a ela. As classes "Dominio", "CompetenciaGeral", "CompetenciaEspecifica" possuem ainda um atributo definicao, que conterá uma breve descrição para cada instância associada às mesmas. As instâncias a serem adicionadas às classes Conhecimento, Habilidade e Atitude não necessitam de descrições além da contida na propriedade nome.

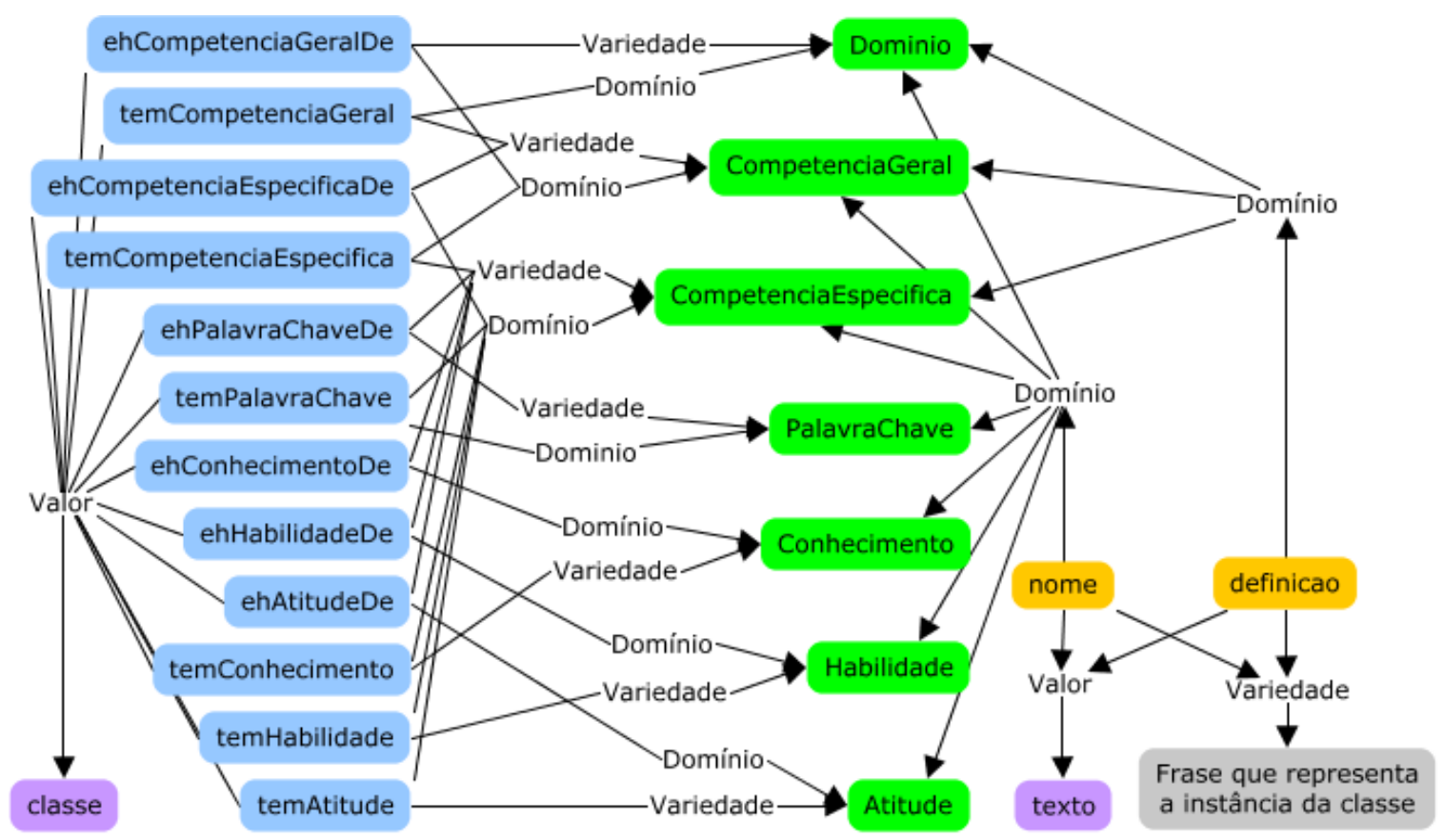

Figura 7: Descrição das propriedades e dos relacionamentos. Simon (2020).

Após a definição das propriedades, é preciso descrevê-las em detalhes. Para os relacionamentos, foram determinados seis pares inversos. Isso garante que as instâncias associadas ao sujeito e ao objeto de um relacionamento se tornem, respectivamente, objeto e sujeito do outro. Assim, o preenchimento de instâncias na ontologia é facilitado. Ao utilizar-se a propriedade inversa, não se faz necessário efetuar associações contrárias através do relacionamento "temCompetenciaEspecifica" se eles forem pares, já que um mecanismo de inferência utilizado no software Protégé as realizará automaticamente. A Tabela 1 apresenta os 6 pares de relacionamentos inversos. 
Tabela 1: Relacionamentos inversos da nova ontologia.Simon (2020).

\begin{tabular}{|c|c|}
\hline A ser preenchido & A ser inferido \\
\hline ehCompetenciaGeralDe & temCompetenciaGeral \\
\hline ehCompetenciaEspecificaDe & temCompetenciaEspecific \\
& a \\
\hline EhPalavraChaveDe & temPalavraChave \\
\hline ehConhecimentoDe & temConhecimento \\
\hline ehHabilidadeDe & temHabilidade \\
\hline ehAtitudeDe & temAtitude \\
\hline
\end{tabular}

Os relacionamentos descritos na Figura 7 podem ser encontrados na Figura 8 que apresenta a representação gráfica da ontologia modelada, construída através da versão 5.2 do software Protégé. Cada retângulo representa uma classe e cada seta conectando os diferentes retângulos consiste em um relacionamento. As propriedades de cada classe não são exibidas nessa figura devido a limitações do Protégé.

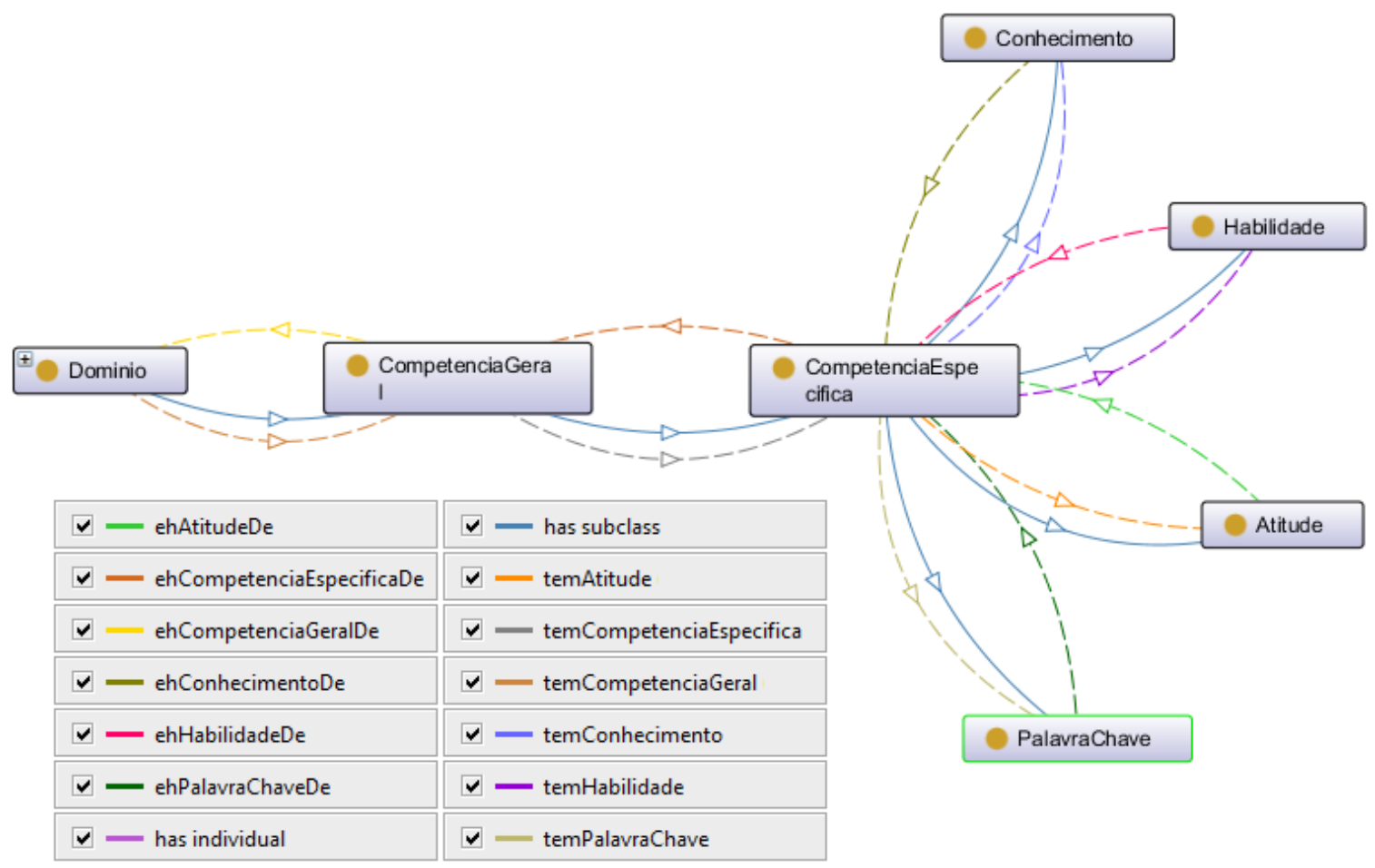

Figura 8: Ontologia com relacionamento entre as suas classes. Simon (2020).

Sexto passo: criação das instâncias. Nesse último passo, foram inseridas instâncias que permitissem o teste da ontologia modelada. Como a base teórica para o modelo de competências seguidas foi a proposta por Behar et al. (2013), não há limitação de domínio a ser utilizado. Optouse então por instâncias baseadas no trabalho de Silva (2018), em que a autora mapeia as competências digitais.

Foram inseridas instâncias para 3 competências gerais, 14 competências específicas, uma das competências específicas recebeu instâncias para 10 elementos de CHA e 13 palavras-chave. O foco dessa validação consistiu na inferência de competências específicas de acordo com as suas palavras-chave associadas.

A Figura 9 ilustra cinco competências específicas que receberam instâncias de palavras-chave associadas. São mostradas também suas classes "Conhecimento", "Habilidade" e "Atitude". A escolha dessas cinco competências em detrimento das outras mapeadas não foi definida por nenhum critério prévio, servindo apenas ao teste da ontologia. Dessa forma foi realizada a análise do uso da ontologia através da aplicação de regras de inferências, descritas na seção seguinte. 


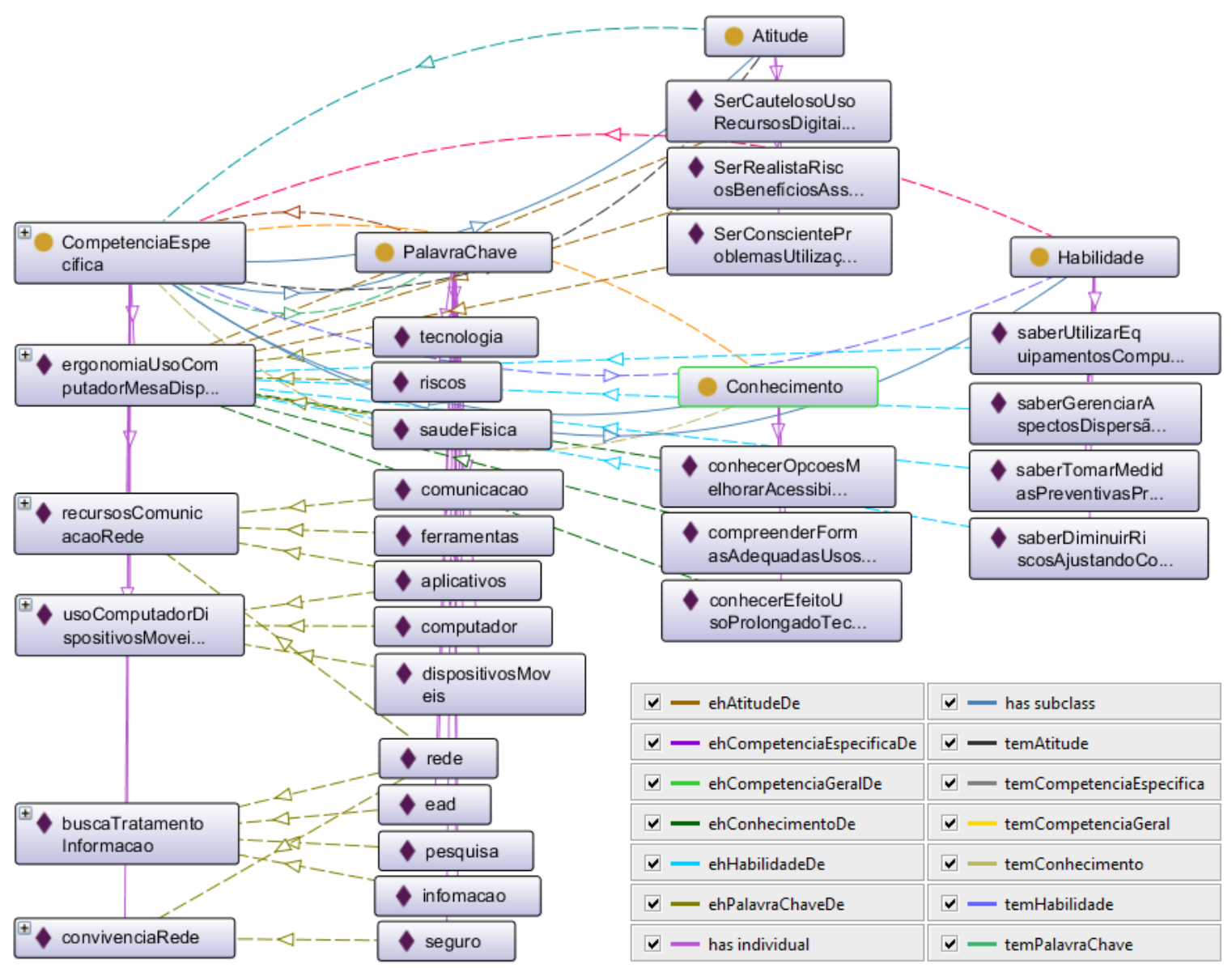

Figura 9: Instâncias do domínio tecnológico.Simon (2020).

\section{Resultados e Discussões}

A verificação da consistência e da ausência de erros na ontologia foi realizada através de um dos sistemas de inferência do Protégé. Dessa forma, foi possível verificar que os axiomas utilizados na ontologia foram corretamente definidos. Com o sistema de raciocínio, utilizando-se regras de inferência, avaliou-se a capacidade da ontologia de responder as perguntas que nortearam o seu processo de modelagem. A avaliação da resposta à primeira pergunta relativa às competências digitais que estariam relacionadas a certos elementos fornecidos, é exemplificada na Figura 10. A partir do fornecimento de três instâncias das classes "Conhecimento", "Habilidade" e "Atitude", o sistema foi capaz de identificar qual instância possui relacionamentos que a liga a esses três elementos. 


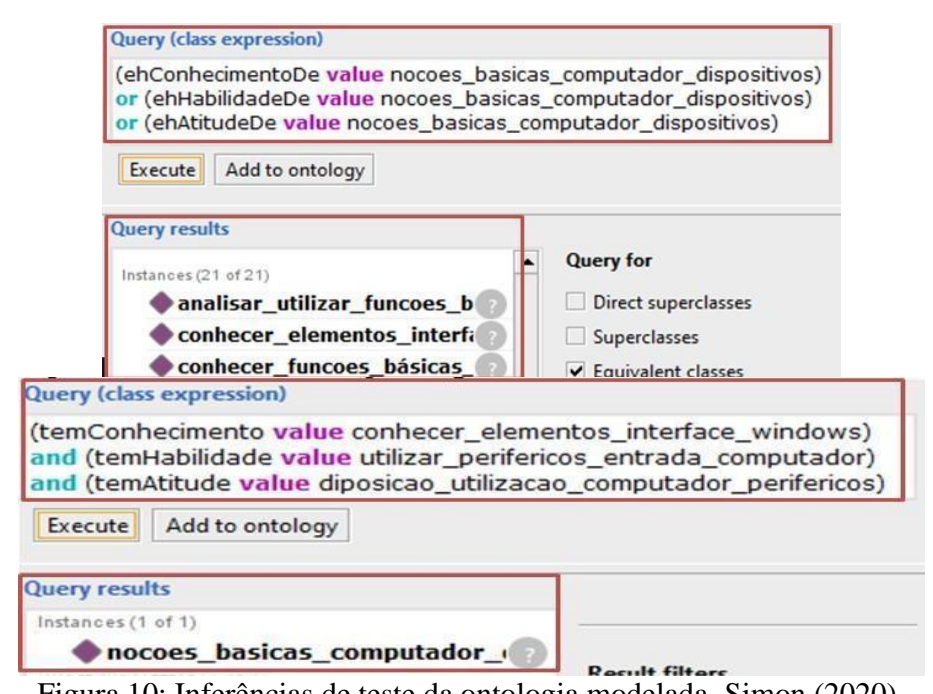

A capacidade de resposta à segunda pergunta, relacionada aos elementos que compõem uma dada competência digital, também é apresentada na Fig. 5. São solicitadas todas as instâncias que possuem os relacionamentos "ehConhecimentoDe", "ehHabilidadeDe" ou "ehAtitudeDe", cujo variedade consiste em uma dada instância da classe "CompetenciaEspecifica". Dessa forma são obtidos todos os elementos do CHA dessa competência. São exibidas 3 das 21 instâncias encontradas.

De forma a testar a recomendação de competências através do uso de palavras-chave, criouse, em caráter de teste, duas classes: AtividadeEnsino, representando atividades de ensino, e ObjetoAprendizagem, representando Objetos de Aprendizagem. Essas novas classes receberam também palavras-chave, de forma que regras de inferências pudessem utilizá-las para a recomendação de competências específicas. A Figura 11 ilustra a simulação da utilização da ontologia em um Sistema de Recomendação de OAs para a sugestão de competências específicas a serem vinculadas a atividades de ensino e OAs. São solicitadas competências que possuam palavras-chave também associadas a uma instância da classe de teste ObjetoAprendizagem.

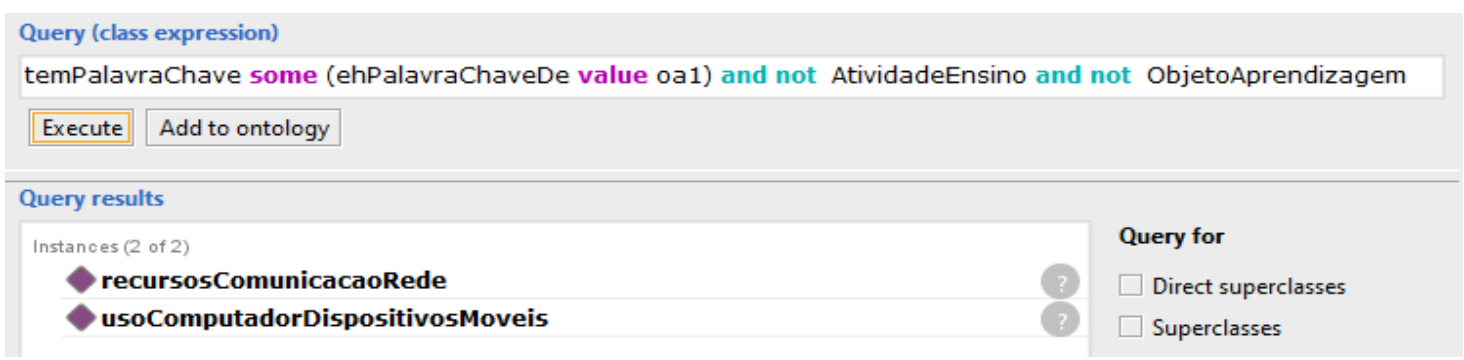

Figura 11: Competências específicas associadas às palavras-chave presentes em um dado OA. Simon (2020).

As atividades desenvolvidas com os alunos de pós-graduação citadas na seção 4 também servirão de base para a modelagem desta ontologia. Tanto os trabalhos realizados pelos alunos como as discussões decorrentes forneceram elementos para determinar quais aspectos de um modelo de competências devem se fazer presentes em uma ontologia de domínio em apoio a SREs. Sendo assim, o trabalho multidisciplinar realizado pelos autores deste estudo em seu grupo de pesquisa, enriquecido pelas atividades desenvolvidas com os alunos de pós-graduação, foi importante não só para a análise da utilização e da modelagem de ontologias na educação, como para a modelagem aqui apresentada. A ontologia de domínio para competências em apoio a SREs, aqui descrita, foi intitulado pela equipe como "OntoCompEdu" (Ontologia de Domínio para 
Competências na Educação) $)^{4}$.

Ainda que não se tratasse da meta principal desta pesquisa, a adaptação da metodologia 101 descrita, traduzindo, simplificando e objetivando algumas de suas etapas, como forma de favorecer o processo de modelagem em equipes multidisciplinares com participantes oriundos de áreas não tecnológicas. Ela foi renomeada para "MetOntoEdu" (Metodologia introdutória para a modelagem de Ontologias na Educação).

Como retorno, através do preenchimento de um dos questionários utilizados na pesquisa, os alunos relataram não ter encontrado obstáculos no processo de modelagem da ontologia utilizando a metodologia modificada. Além disso, ressaltaram alguns pontos positivos afirmando que a nova versão da metodologia facilita o processo de modelagem e a sua organização. Também valorizaram a sua simplicidade, objetividade, adaptabilidade e potencial de auxílio na aprendizagem do processo de modelagem (SIMON, 2020).

Portanto, o presente artigo possui o intuito de divulgar a pesquisa realizada com a finalidade de colaborar com o uso das ontologias na educação, de modo a disponibilizar, à comunidade acadêmica, a ontologia modelada e a adaptação da metodologia 101, a MetOntoEdu. Nesse sentido, a partir do processo de modelagem e análise, entende-se que a ontologia OntoCompEdu apoia o uso de Sistemas de Recomendação baseados em competências, e também demonstra potencial para a sua aplicação em outros SREs. Entretanto, metodologias para avaliação e validação de ontologias ainda precisam ser executadas em trabalhos futuros, além da aplicação prática da OntoCompEdu em um SER baseado em competências.

Assim, considera-se que este estudo possa contribuir para o estado da arte na área, pois, além do compartilhamento de uma ontologia que poderá ser testada em distintos Sistemas de Recomendação por competências, avalia-se uma metodologia modificada para a modelagem de ontologias, com vistas à sua contribuição no apoio à aprendizagem de conceitos de um domínio. Entretanto, o processo de utilização e avaliação da metodologia modificada será apresentado em artigo futuro. Nesse sentido, na próxima seção apresentam-se as considerações finais e os possíveis caminhos para investigações futuras.

\section{Considerações Finais e Trabalhos Futuros}

A modelagem apresentada neste estudo contemplou o objetivo que previa uma ontologia de domínio de competências a ser utilizada em Sistemas de Recomendação na educação. Entretanto, a sua aplicação não se limita a esses sistemas apenas. Tal ontologia foi projetada para contribuir de duas maneiras com os sistemas em que for empregada: (1) na apresentação dos conceitos relativos a competências, objetivando apoiar a compreensão de seus usuários a respeito dessas e dos elementos que as compõem (CHA); como também (2) nos algoritmos utilizados para recuperação de competências específicas mediante a utilização de palavras-chave relacionadas aos seus elementos.

A avaliação inicial da ontologia modelada foi realizada por meio de testes e inferências com o software Protégé, resultando em uma ontologia descrita com a linguagem OWL. A partir disso, serão necessárias ainda duas etapas de validação a realizar: (1) a averiguação da ontologia como modelo de conhecimento, representando o domínio de competências, por especialistas em ontologias; e (2) a utilização da ontologia em um SRE baseado em competências.

\footnotetext{
${ }^{4}$ A ontologia encontra-se disponibilizada no site do Nuted (Núcleo de Tecnologia Digital Aplicada à Educação, da Universidade Federal do Rio Grande do Sul), através do endereço: http://nuted.ufrgs.br/ontocompedu/OntoCompEdu.owl
} 
Nesse cenário, pretende-se implementar a ontologia construída no RecOAComp Recomendador de Objetos de aprendizagem baseado em competências, disponibilizado através do endereço eletrônico http://recoacomp.ufrgs.br. Tal escolha é motivada pelo fato desse SRE utilizar o conceito de competências adotado por Behar et al. (2013) e pela participação dos autores desta pesquisa na equipe que o desenvolve. Basicamente, esse sistema recomenda recursos educacionais digitais aos alunos a partir das competências que eles necessitam construir ou aprimorar (perfil de competências).

Ao realizar login no sistema, o professor, inicialmente, cadastra a sua disciplina, informando as competências que serão abordadas. Após, insere os objetos de aprendizagem que poderão apoiar o desenvolvimento dessas competências, vinculando-os às referidas competências. $\mathrm{O}$ aluno, por sua vez, acessa o RecOAComp, ingressa na disciplina, preenche um formulário de auto avaliação sobre as competências que serão abordadas e solicita a recomendação. Nesse momento são indicados objetos de aprendizagem segundo o seu perfil de competências.

No entanto, durante a utilização desse sistema em diferentes disciplinas de pós-graduação de uma universidade pública, professores comentaram sobre dificuldades enfrentadas na identificação e vinculação de competências às suas disciplinas e objetos de aprendizagem. Nesse sentido, a partir da implementação, no sistema RecOAComp, da ontologia construída, pretendese que competências sejam recomendadas aos professores no momento do cadastro de disciplinas e OAs. Desse modo, os docentes receberão auxílio em seu mapeamento, o que envolve um conhecimento especializado e ainda pouco dominado por muitos educadores.

Além disso, após concluir-se o seu processo de avaliação, objetiva-se disponibilizar publicamente a ontologia construída através da web, com vistas à sua utilização por outros desenvolvedores. É prevista também a ampliação do seu domínio, de forma a representar outros elementos do contexto de SRs baseados em competências, tais como o perfil dos seus usuários, suas atividades de ensino e os itens a serem recomendados. Dessa forma, a ontologia poderá apoiar não apenas a representação dos conceitos envolvidos, mas o processo de recomendação em si. Pretende-se, assim, colaborar com a utilização de ontologias em Sistemas de Recomendação baseados em competências.

\section{Referências}

Al-Yahya, M., George, R.\&Alfaries, A. (2015). Ontologies in E-Learning: Review of the literature. International Journal of Software Engineering and its Applications, v. 9. n. 2. pp. 67-84. [GS Search]

Barto, C., \& Diaz, L.C. (2013). Intelligent Systems Applied to Computer Engineering Teaching. IEEE Latin America Transactions, v. 11, n. 1, pp. 616-618. [GS Search]

Behar, P.A. \&colaboradores. (2009). Modelos Pedagógicos em Educação a Distância. 1ed. Porto Alegre: Artmed. [GS Search]

Behar, P. A., Silva, K. K., Schneider, D., Cazella, S. C., Torrezzan, C. A. W. \& Heis, E. (2015). Development and System Assessment of Learning Object Recommendation based on Competency - RecOAComp. Proceedings of the 7th International Joint Conference on Knowledge Discovery, Knowledge Engineering and Knowledge Management. Anais... Lisboa, Portugal, v.3, pp. 274-280. [GS Search]

Behar, P. A. \& colaboradores. (2013). Competências em Educação a Distância. 1ed. Porto Alegre:Penso. [GS Search] 
Bremgartner, V., Netto, J. F., \& Menezes, C. (2015). Explorando Arquiteturas Pedagógicas Recomendadas por meio de Agentes e Ontologia de Modelo do Aluno em Ambientes Virtuais de Aprendizagem. In: Brazilian Symposium on Computers in Education (Simpósio Brasileiro de Informática na Educação - SBIE). pp. 1157-1166. doi: 10.5753/cbie.sbie.2015.1157 [GS Search]

Cazella, S. C., Behar P. A., Schneider, D., Silva, K. K. \& Freitas, R. (2014). Developing a Learning Objects Recommender System Based on Competences to Education: Experience Report. In: New Perspectives in Information Systems and Technologies. Advances in Intelligent Systems and Computing, v. 276, pp. 217-226. doi: 10.1007/978-3-319-05948-8_21 [GS Search]

Cazella, S. C., Reategui, E.B. \& Behar, P. A. (2010). Recommendation of Learning Objects Applying Collaborative Filtering and Competencies. In: Key Competencies in the Knowledge Society. Springer, Berlin, Heidelberg, pp. 35-43. doi: 10.1007/978-3-642-15378-5_4 [GS Search]

Dolog. P. \&Nejdl, W. (2007). Semantic Web Technologies for the Adaptive Web. In: The Adaptive Web. Springer, Berlin, Heidelberg, pp. 697-719. doi: 10.1007/978-3-540-72079$\underline{9} 23$ [GS Search]

Drachsler, H.,Verbertet, K., Santos, O. C., \& Manouselis, N. (2015). Panorama of Recommender Systems to Support Learning. In: Recommender Systems Handbook. 2. ed. Boston, MA: Springer US, pp. 421-451. doi: 10.1007/978-1-4899-7637-6_12 [GS Search]

Fernández-López, M., Gómez-Pérez, A., Juristo, N. (1997). Methontology: From ontological art towards ontological engineering. Spring Symposium on Ontological Engineering (AAAI). Anais... [GS Search]

Gomez, J. E., Huete, J. F., \&Hernav, V. L. (2016). A Contextualized System for Supporting Active Learning. IEEE Transactions on Learning Technologies. v. 9, n. 2, pp. 196- 202. [GS Search]

Gravilova, T. A., \&Lescheva, I. A. (2015). Ontology design and individual cognitive peculiarities: A pilot study. Expert Systems with Applications, v. 42, n. 8, pp. 3883-3892. [GS Search]

Gruber, T. (2009). Ontology. In: LIU, L.; ÖZSU, M. T. (Eds.). Encyclopedia of Database Systems. 1. ed. Boston, MA: Springer US, p. 1963-1965. [GS Search]

Ibrahim, M. E., Yang, Y., Ndzi, D.L., Yang, G., \& Al-Maliki, M. (2019). Ontology-Based Personalized Course Recommendation Framework. IEEE Access, v. 7, pp. 5180-5199. [GS Search]

Igbal, R., Murad, M.A.A., Mustapha, A., \& Sharef, N.M. (2013). An analysis of ontology engineering methodologies: A literature review. Research Journal of Applied Sciences, Engineering and Technology. v. 6, n. 16, pp. 2993-3000. [GS Search]

Jones, D., T, Bench-Capon, \& Visser P. (1998). Methodologies for ontology development. Proceeding of the 15th IFIP World Conference, pp. 20-35.

Mendes Neto, F. M., \& Sales, A. F. A. (2015). A Recommendation System for Ubiquitous Learning in the Context of Formal and Informal Education. IEEE Latin America Transactions. v. 3, n. 4, pp. 1061-1067. [GS Search]

Morais, E.A.M., \& Ambrósio, A.P.L. (2007). Ontologias: conceitos, usos, tipos, metodologias, ferramentas e linguagens. [GS Search].

Nicola, A.D., Missikoff, M., \&Navigli, N. (2005). A proposal for a unified process for ontology building: UPON. Proceeding of the Database and Expert Systems Applications, pp. 655-664. [GS Search]. 
Noy, N. F., \&Mcguinness, D. L. (2001). Ontology Development 101: A Guide to Creating Your First Ontology. https://protege.stanford.edu/publications/ontology_development/ontology101.pdf.

Øhrstrom, P., Andersen, J., \&Scharfe, H. (2005). What Has Happened to Ontology. In: Dau, F., Mugnier, M.-L.; Stumme, G. (Eds.). Conceptual Structures: Common Semantics for Sharing Knowledge: 13th International Conference on Conceptual Structures, ICCS 2005, Kassel, Germany, July 17-22. Proceedings. Berlin, Heidelberg: Springer Berlin Heidelberg, 2005. p. 425-438.

Paquette, G. (2015). Competency-Based Personalization Process for Smart Learning Environments. In: Learning, Design, and Technology. Cham: Springer International Publishing, pp. 1-36. doi: 10.1007/978-3-319-17727-4_4-1 [GS Search]

Protégé. Recuperado de http://protege.stanford.edu.

Instituto Brasileiro de Informação em Ciência e Tecnologia (IBICT). Repositórios Digitais. Recuperado de http://www.ibict.br/informacao-para-a-pesquisa/repositorios-digitais

RecOAComp. Sistema de Recomendação de Objetos de Aprendizagem baseado em Competências. Recuperado de http://recoacomp.ufrgs.br

Resnick, P., \& Varian, H. R. (1997). Recommender Systems. Communications of the ACM, v.40, n.3, pp. 56-58. Recuperado de https://link.gale.com/apps/doc/A19284343/AONE?u=ufrgs_br\&sid=AONE\&xid=023a812f

Rezende, P. A. A., Pereira, C.K., Campos, F., David, J.M.N., \& Braga, R. (2015). PERSONNA: proposta de ontologia de contexto e perfil de alunos para recomendação de objetos de aprendizagem. Revista Brasileira de Informática na Educação. v. 23, n. 1, pp. 70. doi: 10.5753/rbie.2015.23.01.70 [GS Search]

Ricci, F; Kach, L., \& Shapira, B. (2015). Recommender Systems: Introduction and Challenges. In: Recommender Systems Handbook. 2. ed., Boston, MA: Springer US, pp.1-34. doi: 10.1007/978-1-4899-7637-6_1 [GS Search]

Silva, K. K., \& Behar, P. A. (2016). Mapeamento de Competências Digitais de Estudantes Brasileiros na Educação a Distância. The American Portuguese Studies Association (APSA) International Conference. Anais... Palo Alto, Califórnia: Stanford University, pp.15-24. Recuperado https://www.researchgate.net/publication/317136460_Mapeamento_de_Competencias_Digi tais_de estudantes_Brasileiros_da_Educacao_a_Distancia

Simon, A. (2020). Ontologias na educação: uma proposta de aplicação em sistemas de recomendação. 237 f. Dissertação (Mestrado em Educação) - Faculdade de Educação, Universidade Federal do Rio Grande do Sul, Porto Alegre.

Taurus, J. K., Niu, Z., \& Mustafa, G. (2017). Knowledge-based recommendation: a review of ontology-based recommender systems for e-learning. Artificial Intelligence Review. pp.1-28. [GS Search]

W3C Web Semantic. Recuperado de https://www.w3.org/OWL/.

Wiley, D. (2011). Learning Objects, Content Management, and E-Learning. In: Content Management for E-Learning. New York, NY: Springer New York, pp. 43-54. [GS Search]

Zabala, A., \&Arnau, L. (2014). Como aprender e ensinar competências. Artmed: Porto Alegre. 